\title{
德国 MT 能源公司与美国 DVO 公司厌氧发酵技术简要介绍分析
}

Briefly Introduction and Analysis of Anaerobic Fermentation Technology of Germany MT Energy Company and America DVO Company

\author{
陈子学 丁云朝 刘英学 \\ Zixue Chen Yunchao Ding Yingxue Liu
}

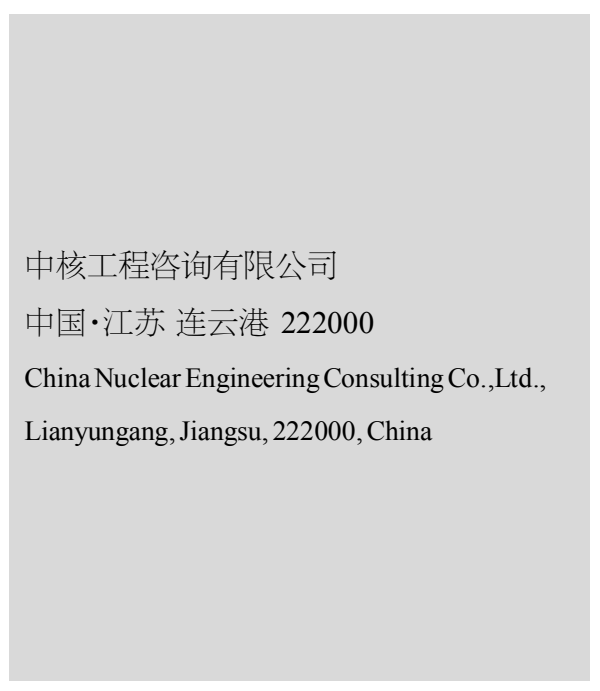

\section{1 引言}

随着国家加大政策导向力度, 近几年在环境治理方面情 况有所改善,但与发达国家相比还相当落后, 对畜禽粪污缺乏 科学经济有效的收集、处理和综合利用技术。厌氧发酵技术因 其在降解有机物的同时可回收能源，被公认是合乎环境可持 续发展要求、最有前景的发展技术之一[1]。畜禽粪便经过固液 分离的液相部分, 以及水冲粪等用水量大的工艺产生的含固 体量较低的固液混合物通常认为是粪水。畜禽有机物大量存 在于固相,需要较长的时间进行厌氧分解, 液相中只存在少量 溶解性有机物, 发酵时间较短[1]。由于畜禽粪养殖场用水量 大,因此产生的水冲粪的含固体量较低,而畜离有机物大量存 在于固相中。目前根据畜昺养殖废水的特点, 厌氧发酵目标是 使畜禽废弃物中的有机物进行降解，降低排放废弃物后造成 的污染。

\section{2 德国 MT 能源公司发酵工艺}

\section{1 技术原理}

MT 发酵技术属于全混式厌氧反应器, 发酔罐内壁铺设 循环加热盘管, 内部设有全自动搅拌装置, 有利于厌氧微生物 和基质良好的接触反应，外部设有保温层。单体罐的容积在 $5000 \mathrm{~m}^{3}$ 。采用混合原料高效厌氧发酵技术, 以粪污和秸秆混合 为主, 发酵原料结构为畜禽粪便 $46.2 \%$; 农作物秸秆 $23.9 \%$; 能源作物 $15.4 \%$; 其他城市及工业有机垃圾 $14.5 \%$ 。

\section{2 工艺简介}

发酵罐采用一体化混凝土浇筑技术, 避免分层浇筑易产 生漏水情况的弊端,罐体顶部配有收集沼气的双膜气柜。畜禽 污水先通过沉沙处理, 然后与粉碎的农作物秸秆混合, 达到一 定浓度后进人厌氧发酵罐。厌氧反应器通常需要 $25 ~ 30 \mathrm{~d}$ 对 物料进行降解反应, 需根据具体的原料特性和工程总体设计 确定, 发酵温度一般 $36^{\circ} \mathrm{C} \pm 2^{\circ} \mathrm{C}$, 原料的含固率要求为 $8 \%$ $10 \%$ 。全混式厌氧反应器常用的机械搅拌有垂直搅拌、侧搅拌 等形式, 发酴罐内部设置了脱硫菌生长设施, 有利于沼气的自 然脱硫(见图 1)。

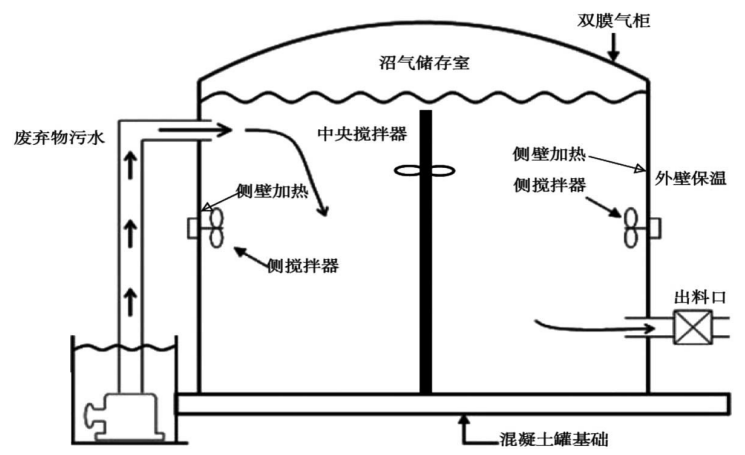

图 $1 \mathrm{MT}$ 发酵技术工艺流程图

\section{3 工艺优势}

(1)合理利用周边的废弃资源, 减少废弃物的污染排放。

(2) 厌氧消化停留时间得到保证, 消化反应器中所有废物

(下转第 36 页) 
是他们中间一定存在着某种关联性, 是不容忽视的, 因此, 这 些数据的关联性也是进行电力系统故障预测的重要参考依 据。可以通过对这些数据的分析来更好地预测出影响设备运 行状态的因素, 然后在实际的运行过程当中, 对这些因素加以 规避来保障电力设备的运行状态良好。

\section{3 电气自动化设备的运行分析与预测}

企业在运行过程当中,应该注意将收集到的大数据进行科 学合理的处理, 保证人才的合理利用, 才能够更好地确保各种 数据发挥最大的价值。因此, 企业要想更加长久平稳地发展, 就 应该增加对高技术人才的录用。目前来说, 中国的时代背景仍 然处于大数据时代, 也就是说数据是人们在发展过程当中应当 关注的重点, 因此, 企业在运行过程当中, 对电气自动化的相关 数据进行数据采集以及统计分析, 已经成为时代必然的发展趋 势。大数据分析能够更好地为电力企业发展提供预测依据, 保 障电力企业发展过程当中的思维, 能够更好地进行创新, 实现 发展过程当中的模式自动化以及智能化 ${ }^{[2]}$ 。

\section{4 电气自动化数据有利于商业模式重塑}

对于电力企业来说, 它的发展过程当中需要进行不断的 商业格局改变, 而电气自动化数据能够更好地为商业模式改 变提供数据基础。电力企业在运行过程当中, 对一些关键性的

\section{（上接第 34 页）}

都有足够的时间完成充分消化。

\section{4 适用范围}

MT 发酵技术适用环境温度较高且气候相对稳定的区 域,周边有足够的混合原料。

\section{3 美国 DVO 公司发酵工艺}

\section{1 技术原理}

DVO 发酵技术为 Two-Stage Mixed Plug Flow TM(两阶段 混合柱塞流)专利技术将混合式与柱塞流工艺合二为一, 并进 行优化。在悉心控制的温度下持续混合各种固形物,采用了先 进先出设计, 从而保证停留时间, 最大程度地提高畜禽废弃物 的消化水平。

\section{2 工艺简介}

DVO 消化反应器采用混凝土地下建造方式, 利用土壤的 天然隔热特性使微生物在最高效率水平下发挥作用。进人厌 氧反应器之前畜禽污水要进行沉沙处理和浓度调配处理。 DVO 厌氧消化器根据仿生学原理, 按照牛的消化系统设计, 层层推进, 反应周期 $22 \mathrm{~d}$ (见图 2)。

\section{3 优势}

(1)厌氧消化停留时间得到保证, 消化反应器中所有废物 都有足够的时间完成充分消化。

(2)消化反应器常年保持温度恒定, 能发挥最大效率。
指标进行统计检测以及分析就能够更好地适应当前社会发展 过程当中的商业格局变化。为电力企业发展过程当中的相关 决策提供更加科学有效的依据。另一方面,随着当前时代科学 技术的不断发展, 电气自动化的数据收集也在不断地更新, 这 对于电力企业商业模式以及管理理念的重塑也起到了非常重 要的影响。总之, 电气自动化数据收集以及数据统计分析能够 更好地为电力企业发展提供助力。

\section{3 结语}

综上所述, 电气自动化的数据收集和统计分析对于变电 站的正常运行有着非常重要的作用, 它可以及时地反映变电 站的运行状态, 为监督检测提供数据支持。通过监督检测系统 获取数据并加以处理和分析, 可以生成检测报告, 然后再根据 检测报告的相关数据制定合适的解决措施，保障变电站在使 用过程当中一直处于安全稳定的状态。

\section{参考文献}

[1]万朋成.电气自动化的数据收集和统计分析[J].民营科技,2018 (2):31.

[2]王来基.浅谈电气自动化数据收集及数据统计分析 $[\mathrm{J}]$.西部皮 革,2017,39(2):267.

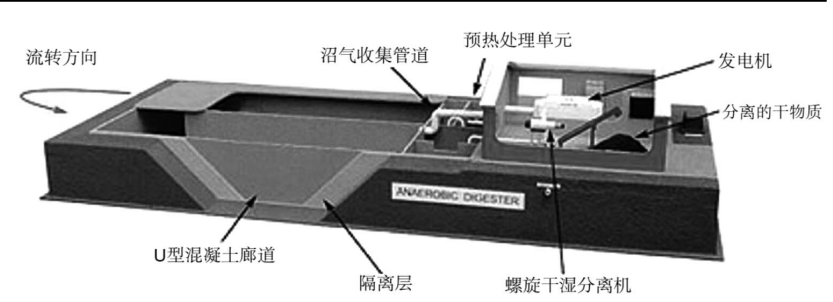

图 2 DV0 消化反应器工艺流程图

\section{4 适用范围}

DVO 发酵技术适用于寒冷区域, 对于原料的含固率不做 要求。

\section{4 结语}

近年来, 中国对环境保护高度重视, 鼓励利用新技术、新 能源, 以减轻温室效应和促进生态良性循环。对畜禽养殖业的 污水排放问题高度重视，并且颁布了很多畜禽粪污处理的政 策法规, 在保证良好的经济效益和环境效益的前提下, 引进国 外粪污处理技术进行学习和融合, 是解决畜禽养殖业污水处 理的有效途径之一。

\section{参考文献}

$[1]$ 盖希坤,张良佺.畜禽废水厌氧反应动力学研究 $[\mathrm{J}]$.农业机械学 报,2017,44(1):245-251.

[2]李晨艳,乔玮,邵蕾,等. 厌氧发酵技术在畜禽养殖粪水处理与资 源化中的利用[J].猪业科学,2017,34(5):92-94. 